\title{
Laser Multi-Pass Narrow-Gap Welding - A Promising Technology for Joining Thick-Walled Components of Future Power Plants
}

\author{
Benjamin Keßler ${ }^{1, *}$, Berndt Brenner $^{1}$, Dirk Dittrich ${ }^{1}$, Jens Standfu ${ }^{1}$, Eckhard Beyer ${ }^{1 / 2}$, Christoph Leyens ${ }^{1 / 2}$ and \\ Gerhard Maier $^{3}$
}

\author{
${ }^{1}$ Fraunhofer IWS Dresden, Winterbergstraße 28, 01277 Dresden, Germany \\ ${ }^{2}$ Technische Universität Dresden, 01062 Dresden, Germany \\ ${ }^{3}$ Fraunhofer IWM Freiburg, Wöhlerstraße 11, 79108 Freiburg, Germany
}

\begin{abstract}
Today, the average worldwide efficiency of coal-fired power plants stands at about 33 percent. The consistent use of state of the art technologies would enable an increase of the average efficiency of up to 47 percent and thus a sharp reduction of greenhouse gas emissions. The importance of improvements in this field becomes apparent when reviewing e.g. plans in Europe in 2017 for new power plants to be built across the continent. About 44 percent of the envisaged 153 gigawatts are still to be generated by fossil-fuel power plants [1]. One technical solution is to increase the steam turbine inlet temperature to $700^{\circ} \mathrm{C}$. This, however, requires the use of nickelbased superalloys. Only these alloys satisfy all the requirements with regard to high-temperature, corrosion and oxidation resistance and creep behavior [2], [3]. Due to their relatively poor machinability, forgeability and high material costs compared to the steel-based alloys they are to replace, a more effective welding technology is needed to overcome the disadvantages of conventional welding technologies, i.e. large quantities of filler metal required and high energy input per unit length resulting in distortion and the potential reduction of high-temperature properties.
\end{abstract}

\section{Introduction and motivation}

Tungsten Inert Gas (TIG)-narrow gap welding is still the state of the art and most investigated technology for joining thick-walled parts for high-temperature and highpressure applications in modern power plants to produce weld seams according to quality requirements (e.g. [4]). This welding technology is characterized by low welding speeds $(<0.1 \mathrm{~m} / \mathrm{min})$ and high heat input per unit length $(>15 \mathrm{~kJ} / \mathrm{cm})[5,6]$. In combination, these technological limits could lead to high component distortion and possible weld imperfections in nickel superalloys such as:

- hot solidification cracking

- liquation cracking and/or

- ductility-dip cracking

- lack of fusion due to high viscous melt

- significant shrinking due to enormous hightemperature strength and

- loss of alloying elements [2], [7-10]

As a consequence, a multi-pass welding technology needs to be developed to overcome these limitations and to ensure the economic, innovative and low-damage production of components such as reheaters, pipes and valves for example by using Alloy 617B/occ [11] The approach is to develop what we call the laser multipass narrow-gap (Laser-MPNG) welding technology. This paper will present the advantages of the new technology, the developed welding equipment and the results of welding tests in the lab as well as first results of low cycle fatigue properties at $700^{\circ} \mathrm{C}$.

\section{Approach: Laser-MPNG}

Laser multi-pass narrow-gap welding is based on using high-brilliant laser beam sources with low laser beam power of up to $5 \mathrm{~kW}$ and $\mathrm{V}$-shaped weld seam preparation to overcome the technical limits with regard to possible welding depths in laser beam welding. The excellent beam quality of modern laser beam sources provides the opportunity to prepare weld seams with minimized opening angles $\left(4^{\circ}\right)$ and gap widths at the bottom of down to $1.5 \mathrm{~mm}$ because of the good focusability of the laser beam.

The technological approach is to weld the root with a static laser beam before filling the welding gap with a filler wire using a fast oscillating laser beam to ensure 
that the two joining partners and the filler wire can be melted with drastically reduced heat input per unit length compared to conventional welding technologies [12]. A schematic illustration of Laser-MPNG can be found in Figure 1.

The main advantages of Laser-MPNG are:

- drastically reduced weld seam volume leading to high productivity and the use of less filler material

- low heat input per unit length leading to minimized base material damage and

- drastically reduced distortion as well as

- high potential for automation to eliminate quality issues.

The welding technology could be used for all materials, but demonstrates its advantages in comparison to conventional welding technologies particularly while producing weld seams in thick-walled components made of materials that are hard to weld. The range of materials that have already been investigated ranges from aluminum alloys [13] to high-temperature steel alloys and the nickel superalloy presented in the following.

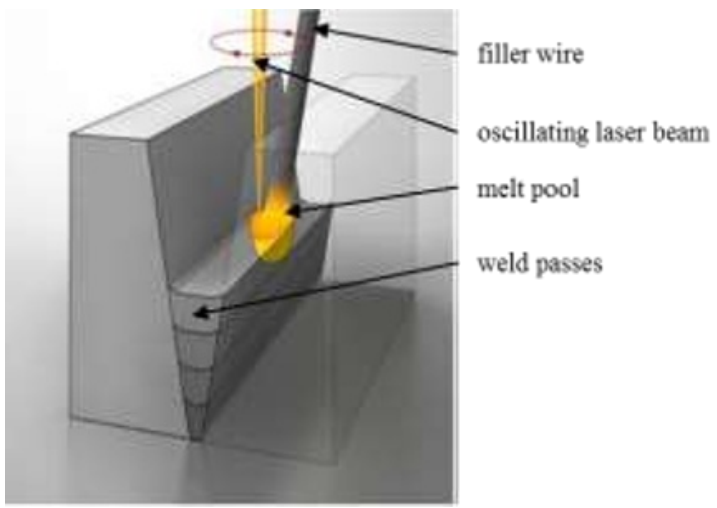

Fig. 1. Basic principle of the Laser multi-pass narrow-gap welding process (Laser-MPNG)

\section{Welding optics remoweld ${ }^{\circledR}$ MPNG}

The welding process was developed with the help of a specifically designed welding head prototype to meet the following requirements:

- ability to join parts of up to $250 \mathrm{~mm}$ wall thickness

- transmit a laser beam with power of up to $5 \mathrm{~kW}$

- flexible positioning of the filler wire

- contact-free gap measuring sensors (width and depth)

- integrated process observation

- $\quad$ automated logging of process parameters

The developed remoweld ${ }^{\mathbb{R}}$ MPNG welding head prototype (Figure 2) fulfills all the requirements and consists of different modules to adapt the welding head for different joining tasks and customer demands.

The high aspect ratio (gap depth/gap width) required a completely new strategy for gap measuring. The solution to this problem is a combination of a triangulation sensor to measure the gap depth and a capacitive sensor for measuring the gap width with two sensors on each side to ensure the central position of the welding process in the welding gap.

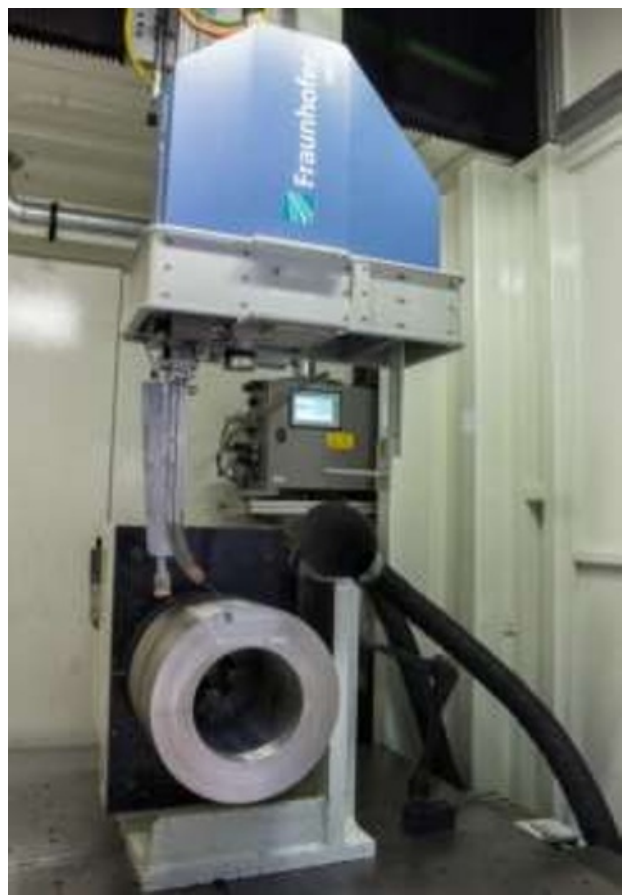

Fig. 2. remoweld ${ }^{\mathbb{R}} \mathrm{MPNG}$ weld head prototype

In combination with a central control and processing unit, the welding process data and welding gap dimensions for each pass of the weld seam can be logged (Figure 3). In addition a high-speed video for optimized process control and quality assurance is made by the included process observation unit.

Currently the focus of further research and development activities is on creating an IT infrastructure in form of a database for smart analysis in order to use artificial intelligence to improve welding parameters.

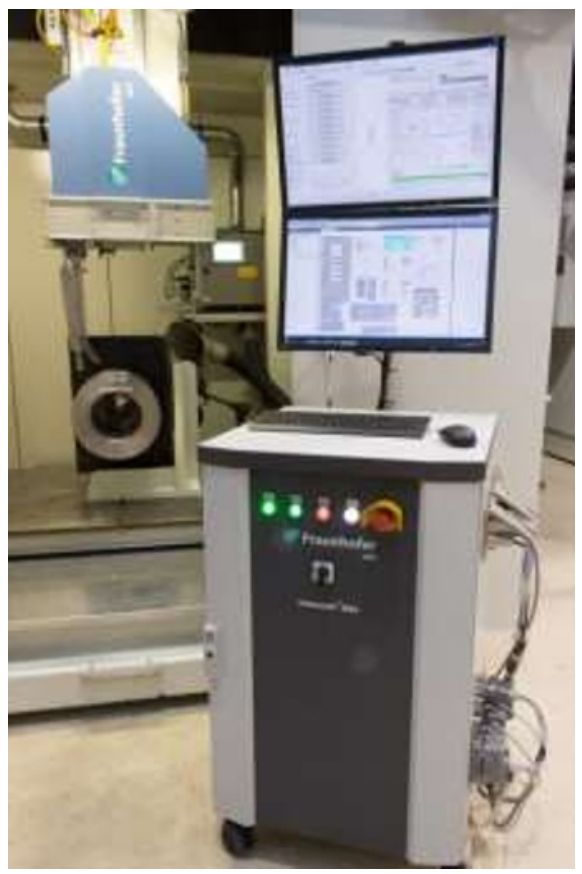

Fig. 3. Central control and processing unit 


\section{Experimental set-up}

The process was developed with a multimode fiber laser with a maximum laser power of $4 \mathrm{~kW}$, a core diameter of $50 \mu \mathrm{m}$ and BPP of $2 \mathrm{~mm} \bullet \mathrm{mrad}$ and the remoweld ${ }^{\mathbb{R}}$ MPNG.

The Alloy 617 occ test material with an outstanding high-temperature strength and very good oxidation and corrosion resistance is a derivate of Alloy 617 which has been improved for weldability e.g. lower carbon content compared to Alloy 617. The alloy is melted and remelted in a vacuum furnace and the Boron concentration is very precisely controlled $[14,15]$.

A comparison of the chemical composition according to [11] and the chemical composition of the test material can be found in Table 1 .

Table 1. Chemical composition in weight $\%$ of Alloy $617 \mathrm{occ}$ and the test material [11]

\begin{tabular}{l||l|l|l}
\multirow{2}{*}{ Element } & \multicolumn{2}{l}{ Alloy 617 occ } & \multirow{2}{*}{ Test material } \\
\cline { 3 - 4 } & min & $\max$ & \\
\hline \hline $\mathrm{Ni}$ & bal. & & bal. \\
\hline $\mathrm{Cr}$ & 21,0 & 23,0 & 21,88 \\
\hline $\mathrm{Co}$ & 11,0 & 13,0 & 11,49 \\
\hline $\mathrm{Mo}$ & 8,0 & 10,0 & 8,47 \\
\hline $\mathrm{Ti}$ & 0,25 & 0,5 & 0,43 \\
\hline $\mathrm{Al}$ & 0,8 & 1,3 & 1,21 \\
\hline $\mathrm{Fe}$ & - & 1,5 & 0,66 \\
\hline $\mathrm{Mn}$ & - & 0,5 & 0,34 \\
\hline $\mathrm{Si}$ & - & 0,3 & 0,06 \\
\hline $\mathrm{C}$ & 0,05 & 0,08 & 0,056 \\
\hline $\mathrm{P}$ & - & 0,012 & 0,006 \\
\hline $\mathrm{S}$ & - & 0,008 & 0,005 \\
\hline $\mathrm{V}$ & $>0$ & 0,6 & 0,3 \\
\hline $\mathrm{Nb}$ & $>0$ & 0,6 & 0,17 \\
\hline $\mathrm{B}$ & 0,001 & 0,005 & 0,004 \\
\hline \multicolumn{2}{|l}{} & & \multicolumn{2}{|l}{} \\
\hline
\end{tabular}

The welding tests were carried out on pipe segments with an outer diameter of $350 \mathrm{~mm}$ and a wall thickness of $72.5 \mathrm{~mm}$. Typical weld seam preparations can be found in Figure 4 .

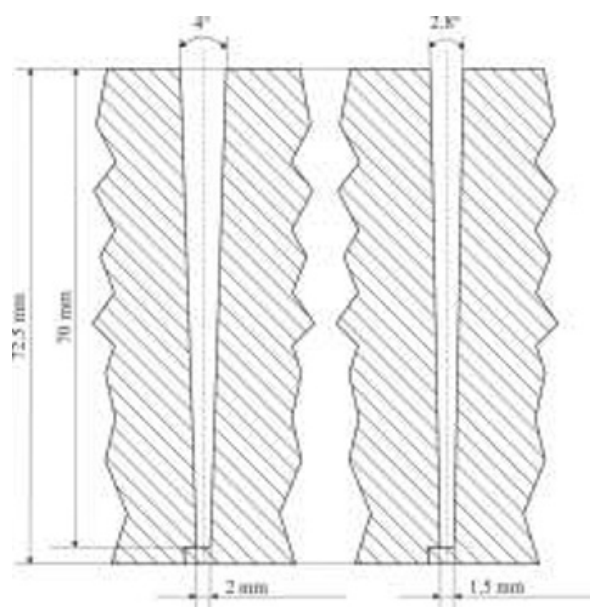

Fig. 4. Typical weld seam preparations for Laser-MPNG with a root seam geometry for lab tests
During the development of the process the opening angle of the seam could be reduced from 4 to 2.8 degrees. The advantage of reducing the opening angle is apparent: Because of reduction of the weld seam volume, the welding seam can be built up with one weld bead per pass and process efficiency can be increased. However, the precision requirements on positing of the laser beam to the parts become more difficult, because there is the risk that the laser beam interacts with the flanks or surfaces of the parts.

\section{Laser-MPNG Findings and discussion}

The process was developed in a number of steps starting with bead-on-plate test trials:

\subsection{Static laser beam}

Figure 5 illustrates the results of the first step. The diagram shows the welding penetration of the optical setup used for Alloy 617occ by using 2 and $4 \mathrm{~kW}$ laser beam powers at different welding speeds.

It can be noticed that the Ni-based alloy shows the typical shape of a nail head due to the poor thermal conductivity especially in the typically used welding speed range of Laser-MPNG of 0.7 to $2 \mathrm{~m} / \mathrm{min}$. On the one hand, this could be used to melt base and filler material effectively without losing energy through the conduction of heat to the joining partners. On the other hand, there is a risk of overheating the melting pool which can lead to the vaporisation of the alloying elements and ultimately compromises the hightemperature properties of Alloy 617occ.

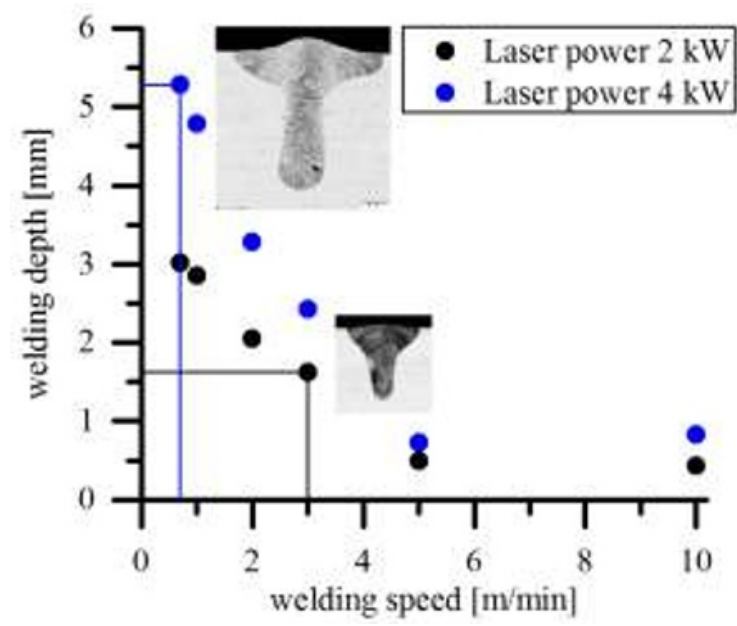

Fig. 5. Correlation between welding speed and welding depth

\subsection{Oscillating laser beam}

The second step was designed to work out the effect of laser beam oscillation. The mathematical description for the harmonic oscillation can be found in equation (1):

$$
\left(\begin{array}{l}
x_{\text {Laser }}(t) \\
y_{\text {Laser }}(t)
\end{array}\right)=\left(\begin{array}{c}
a_{X} \sin \left(2 \pi f_{X} t\right) \\
a_{Y} \sin \left(2 \pi f_{Y} t+\Delta \varphi\right)
\end{array}\right)
$$


Legend:

$\mathrm{a}_{\mathrm{x}} \quad$-amplitude in weld direction

$\mathrm{a}_{\mathrm{y}}$-amplitude transversal to weld direction

$f_{x} \quad$ oscillation frequency in weld direction

$\mathrm{f}_{\mathrm{y}} \quad$ oscillation frequency transversal to weld direction

$\Delta \varphi \quad$-phase shift

Two different oscillation strategies were investigated as part of the development of the welding process:

a) oscillation figure with a frequency ratio of 1 , in the following referred to as "pattern 1" (Figure 6 , left) and

b) oscillation figure with a frequency ratio of 0.5 and a phase shift of $\pi / 2$, in the following refered to as "pattern 2" (Figure 6, right)

Figure 6 displays the different cross-sections (energy per unit length was the same in both cases) of the different oscillation figures.

It can be found that pattern 1 shows an asymmetric solidification form, which can cause a lack of fusion to the side walls. Pattern 2 doesn't show an asymmetric solidification structure.

A look at the welding efficiency [16] calculated by equation (2) yields the following result:

$$
W E\left[\frac{m^{3}}{k J}\right]=\frac{A \cdot v_{s}}{P_{L}}
$$

Legend:

WE - welding efficiency

A - cross-section area of the micrograph

$\mathrm{v}_{\mathrm{s}} \quad$ - welding speed

$\mathrm{P}_{\mathrm{L}} \quad$ - laser beam power

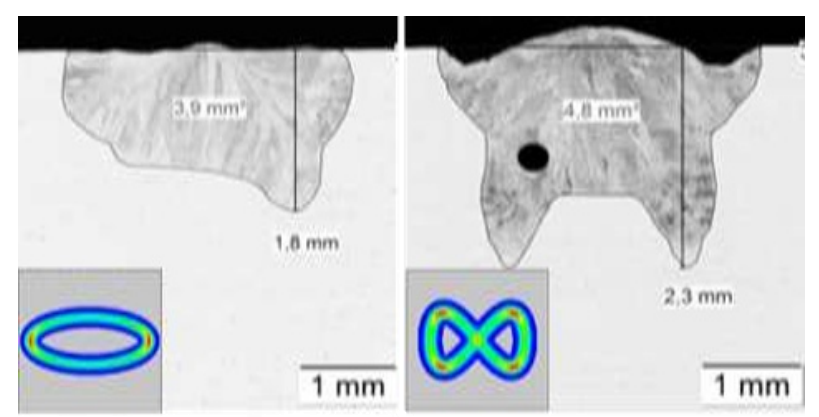

Fig. 6. Left: pattern 1, right: pattern 2

The resulting welding efficiency of pattern 2 $\left(40 \mathrm{~kJ} / \mathrm{mm}^{3}\right)$ is higher than that of pattern 1 $\left(32.5 \mathrm{~kJ} / \mathrm{mm}^{3}\right)$. This means that pattern 2 transforms the laser beam power more effectively into the plate than pattern 1.

Based on these tests, the pattern 2 was used for further developing the welding process.

\subsection{Welding of pipe elements}

After the bead-on-plate tests, the main welding experiments were performed on pipe segments. Figure 7 shows a Laser-MPNG weld sample with the seam preparation as shown in Figure 4 to the right.

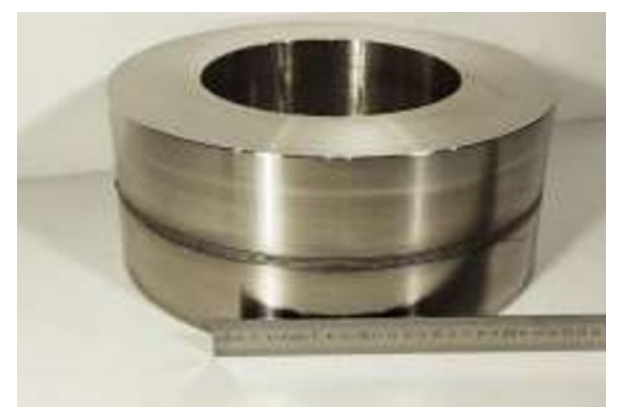

Fig. 7. Laser-MPNG test weld: outer diameter $350 \mathrm{~mm}$ and wall thickness $72.5 \mathrm{~mm}$

The weld seam was produced pass by pass with the gap being measured during the application of each of the passes. The development showed that measuring is required to adjust the oscillation amplitude transversal to the welding direction. Because of component distortion this is essential to ensure the high quality of the weld seam. Otherwise there would be a high risk for getting lack of fusions to the side walls caused by an oscillation width which is too low or too high. The determination of the oscillation width depends mainly on two welding parameters, namely laser beam power and gap width. During the development of the process we found that the oscillation width should be equal or a slightly lower than the gap width at the bottom of the weld seam.

Figure 8 shows a detailed view of a Laser-MPNG welding seam. It can be seen that the process can be characterized by a high homogeneity of the different weld seam passes and excellent joining results between the weld zone and base material.

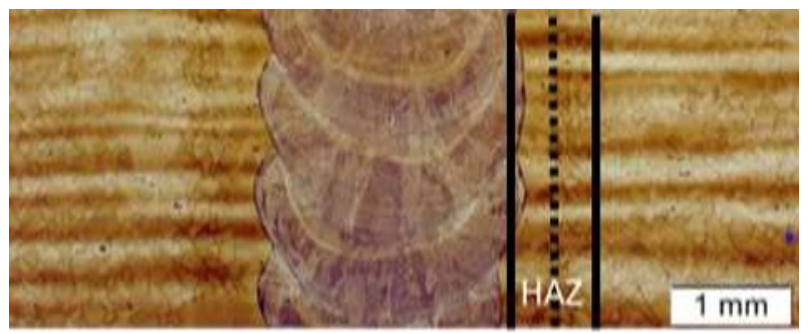

Fig. 8. Micrograph of a Laser-MPNG weld in Alloy 617occ with a $H A Z<1 \mathrm{~mm}$

The solidification structure shows a relatively coarse structure with fine ball-shaped precipitations (e.g. Al-oxide, Ti-nitride and Mo-rich carbides). The minimized heat input per unit length of a maximum of $4.2 \mathrm{~kJ} / \mathrm{cm}$ leads to a very narrow $(<1 \mathrm{~mm})$ heat-affected zone (HAZ) in the base material.

Another micrograph of a weld seam and three details of this weld seam can be found in Figure 9. The micrographs display the differences in solidification behaviour of the weld bead in different welding depth of a welding trial with a wall thickness of $72.5 \mathrm{~mm}$. The bottom of the welding seam is characterized by low laser beam power $(\sim 2 \mathrm{~kW})$ and smaller oscillation width leading to a homogeneous cross section. The close-ups 
provided in Figure 9, b) and c) show a different solidification form compared to a). The oscillation frequency in those cases is the same as in a) which causes a different local welding speed due to the different moving velocities of the mirrors in the galvanometer scanner. The higher speed of the laser beam in the middle of the weld seam causes a smaller penetration and therefore the solidification form is characterized by two peaks at the turning points. At these peaks there is the risk of pores forming (Figure 9, b) because of local overheating of the weld bead and very high solidification rates.

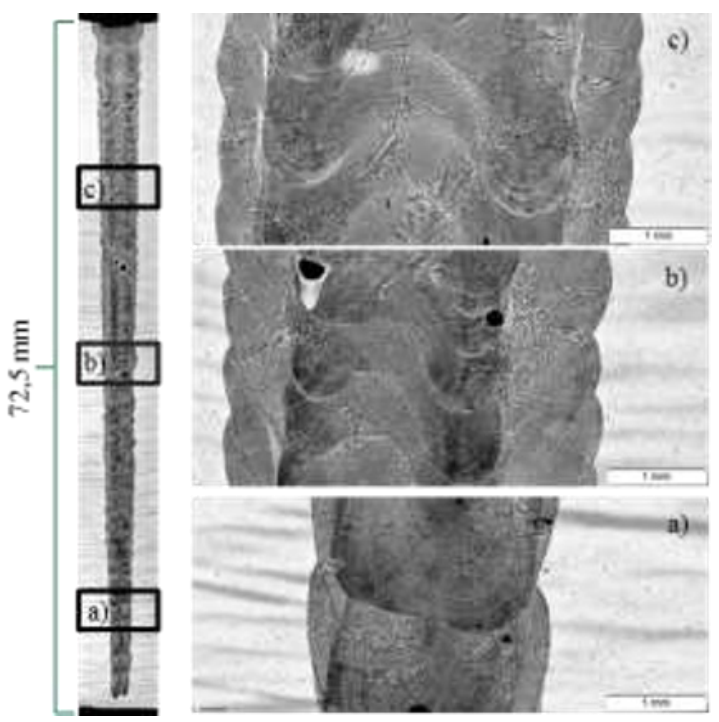

Fig. 9. Macro-section of a welding seam with a welding depth of $72.5 \mathrm{~mm}$ and details of the welding seam

\subsection{Weld seam characterization}

Because of the different welding parameters in different welding depths, the micro hardness (HV0.1) was measured in different regions of the weld seam. The result can be seen in Figure 10.

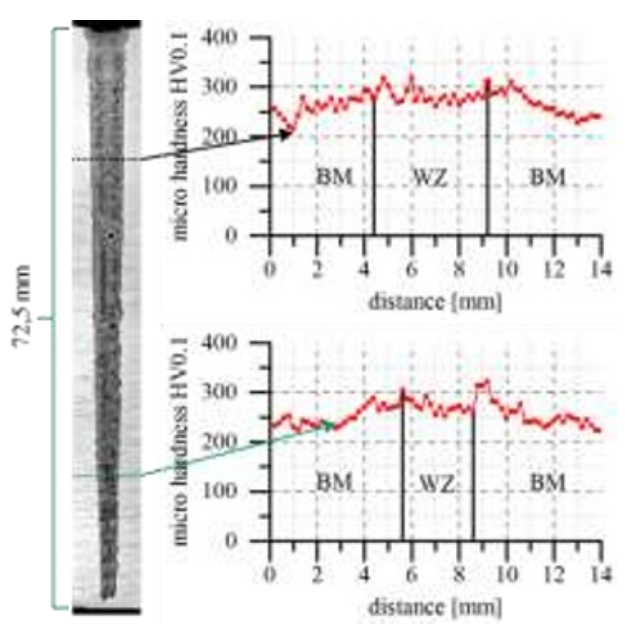

Fig. 10. Macro-section of a welding seam with a welding depth of $72.5 \mathrm{~mm}$ and measurements of micro-hardness in two different welding depths (BM - base material, WZ - weld zone)
The measurements of this sample without postweld heat treatment (PWHT) show that there are no differences in the hardness in the weld seam. In the welded zone there is a small increase in hardness compared to the base material. However, these small differences could be reduced after PWHT $\left(980^{\circ} \mathrm{C} / 3 \mathrm{~h}\right)$.

Different mechanical tests were performed to determine the mechanical properties of the weld seam. At this point, the focus should be on low-cycle fatigue behavior at $700^{\circ} \mathrm{C}$ in specimens with weld seams comparable to the base material. The specimen shape that was used is shown in Figure 11. The tests were performed with a constant strain rate of $\mathrm{d} \varepsilon / \mathrm{dt}=1 \mathrm{e}-3 \mathrm{1} / \mathrm{s}$ at different levels of strain amplitude.

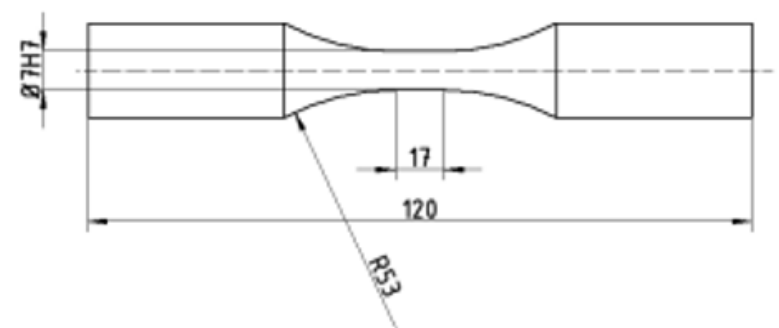

Fig. 11. Specimen shape for LCF test

The results are shown in Figure 12. The graph shows the cycles until the initiation of cracks in base material specimens and cross-weld specimens extracted from different weld seams. The results show that:

- the base material in the as received and stabilized $\left(980{ }^{\circ} \mathrm{C} / 3 \mathrm{~h}\right)$ material condition shows an excellent LCF behavior at $700^{\circ} \mathrm{C}$, within the existing scatter band from [17]

- lifetime of cross-weld specimens lies within a scatter band of factor two of the base material

- in most cases crack initiation in cross-weld specimens occurs near small defects in the weld seam e.g. pores or (aluminum) oxides.

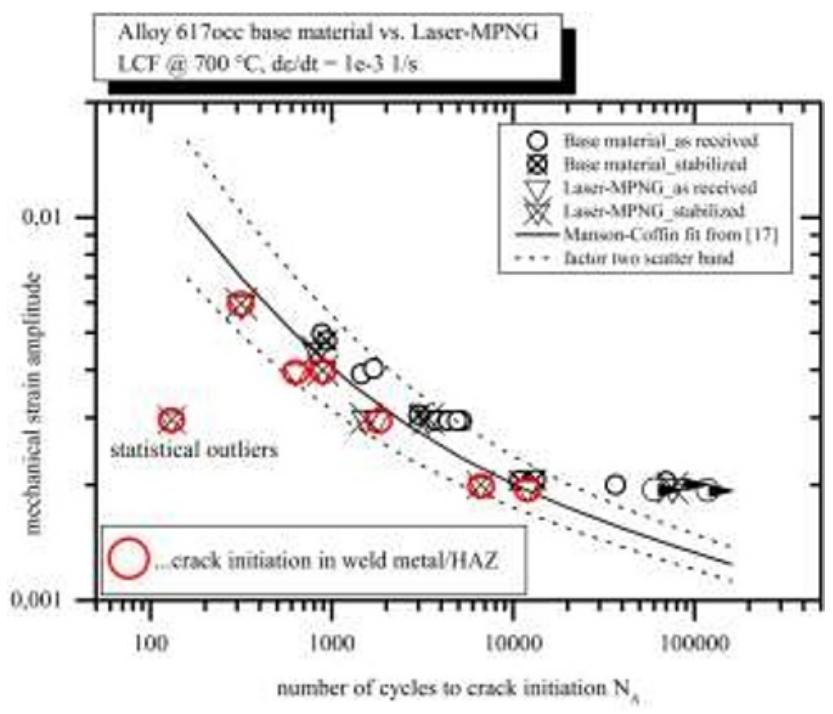

Fig. 12. Low-cycle fatigue behavior of Alloy 617 occ base material and cross-weld specimens at $700^{\circ} \mathrm{C}$ 
In conclusion it can be found that Laser-MPNG has a negligible influence on LCF lifetime of Alloy 617 occ. Further investigations on VHCF-behavior, creep and creep-fatigue lifetime are still being conducted and further findings will be presented soon.

\subsection{Comparison to TIG-narrow gap welding}

Figure 13 shows a comparison of a TIG-welding sample and two Laser-MPNG welding samples.

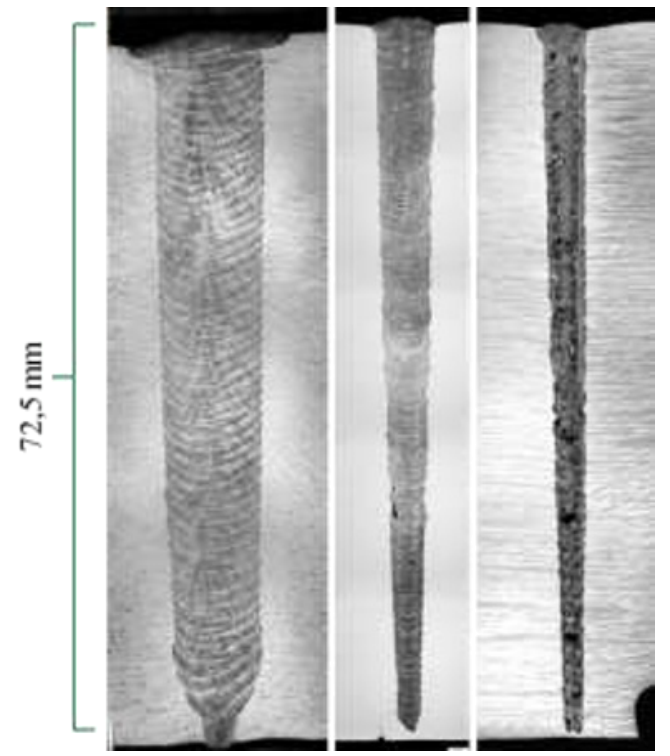

Fig. 13. Macrographs of a welding seam with a welding depth of $72.5 \mathrm{~mm}$ and measurement left: TIG (data from ENCIOproject), middle: Laser-MPNG with two weld beads per pass in the upper region and right: Laser-MPNG with one weld bead per pass from top to bottom

Both welding technologies are characterized by the homogeneous built-up of passes. TIG-welding has a seam opening angle of $\sim 10^{\circ}$ while this angle can be reduced to $2.8^{\circ}$ by using Laser-MPNG which results in a weld seam volume up to 60 to $80 \%$ lower than that of TIG-welding. The maximum deposition rate used with Laser-MPNG welding with $1400 \mathrm{~g} / \mathrm{h}$ and a welding speed of $\sim 1 \mathrm{~min} / \mathrm{min}$ are considerably higher than 265 $\mathrm{g} / \mathrm{h}$ and $0.5 \mathrm{~m} / \mathrm{min}$ while TIG-welding. The number of passes required by Laser-MPNG is higher, but is compensated for by the higher deposition rate and welding speed.

In summary, this comparison shows the enormous potential of Laser-MPNG for its economic use and replacing existing welding technologies.

\section{Summary and conclusion}

The objective of the given research and development results was to develop the Laser-MPNG welding technology to join pipe perspectival elements made of Alloy 617 occ.

As a precondition it was necessary to design and test the suitable welding equipment to meet the special requirements of the welding process. Therefore, the remoweld ${ }^{\mathbb{B}} \mathrm{MPNG}$ welding head prototype with an integrated camera-based monitoring system and gapmeasuring sensors was designed and tested in combination with the central process and control unit. The welding head enables the possibility to use LaserMPNG to produce weld seams that meet the quality requirements according to international standards.

The welding process was developed in different steps starting with bead-on-plate test which showed that the oscillation parameters do have a high influence on welding efficiency and solidification structures.

The bead-on-plate tests were followed by the welding of pipe segments. These welding tests show that the welding process is repeatable and causes low local influence through heat input in the base material (very narrow HAZ). The weld seams are crack-free and show no lack of fusions (neither to the flank nor between the passes). When the welding efficiency was raised by increasing the deposition rate of filler wire pores could be overserved. These pores are still under investigation. The findings with regard to the mechanical properties of the welding seams produced by Laser-MPNG especially low-cycle-fatigue behaviour at $700^{\circ} \mathrm{C}-$ show that the weld seams are nearly at the same level as the base material (within the scatter band). This finding is very relevant with regard to the potential application of the Laser-MPNG technology since there is almost no loss of high-temperature strength caused by the welding process.

The presented results are the result of a strategic partnership involving Fraunhofer IWS, Fraunhofer IWM and Fraunhofer IKTS and were supported by the FhG Internal Programs under Grant No. WISA 828505 . The partners would like to thank all those involved for their support. On behalf of the institutions involved, the authors would like to thank our partners for their support.

\section{References}

1. N.N., Electricity Generation 2017/2018 - Facts and Figures, VGB PowerTech e.V., (2017)

2. V. Knezevic et al., Procedia Engineering Creep Behaviour of Thick-Wall Alloy 617 Seamless Pipes for $700^{\circ} \mathrm{C}$ Power Plant Technology, Nr. 55, p. 240-245, (2013)

3. X. Xie et al., Superalloys for Advanced UltraSuper-Critical Fossil Power Plant Application" Chapter 3. P.51-76

4. D. Di Gianfracesco, Elsevier Science \& Technology Materials for Ultra-Supercritical and Advanced Ultra-Supercritical Power Plants", (2016)

5. H. W. Ahmad et al., Metals Welding Residual Stress Analysis and Fatigue Strength Assessment of Multi-Pass Dissimilar Material Welded Joint between Alloy 617 and 12Cr Steel, 8 (2018)

6. S. Li et al., Journal of Materials Processing Technology, Behavior of M23C6 phase in Inconel $617 B$ superalloy during welding, Vol. 258, p. 3846, (2018), 
7. A. Klenk, Cluster-Forum Schweißtechnik im Kraftwerksbau, SLV München, Anforderungen an Schweißverbindungen in Hocheffizienzkraftwerken", (2009)

8. B. Kuhn et al., FVW/FVHT, 34. Vortragsveranstaltung, Beurteilung des Stress-Relaxation-/ Strain-Age-Cracking- Verhaltens von Alloy 617B und dessen Schweißverbindungen", (2011)

9. J. Mentz et al., Einfluss der Wärmebehandlung auf die Relaxationsrissneigung und die Heißrissneigung von Alloy $617 B$

10. H. Xu et al., Materials Characterization , Evolution of carbides and its characterization in HAZ during $N G$-TIG welding of Alloy 617B", Vol. 130, p. 270277 (2017)

11. N.N., Hochwarmfeste Nickelbasislegierung $\mathrm{NiCr} 23 \mathrm{Co} 12 \mathrm{Mo}$; Werkstoff-Nr. 2.4673 Stab, Schmiedestück - WB 573; Verband der TÜV e. V., Köln, (2013)

12. G. Göbel et al., Proc. of 26th ICALEO, New Application possibilities for fiber laser welding, (2007)

13. Dittrich, D et al., Schweißen und Schneiden Laserstrahl-Mehrlagen-Engstspaltschweißen zum verzugsarmen und heißrissfreien Fügen von Aluminiumlegierungen im Dickblechbereich", Vol. 3, p. 114-117, (2015)

14. J. Klöwer et al., Procedia Engineering Development of Nickel Alloys Based on Alloy 617 for Components in $700^{\circ} \mathrm{C}$ Power Plants, Vol. 66, p. $226-231$

15. N.N., ThyssenKrupp AG, Press release, Higher efficiency, less $\mathrm{CO}_{2}$, New material for 700-degree power plants ready for practical test phase, (2010)

16. S. Ream, ThyssenKrupp AG, Press release, Trends \& Keys to Success In Laser Welding, (2016)

17. M. Speicher et al., Advances in Materials Technology for Fossil Power Plants, Proc. of 8. Int. Con., Albufeira, 2016, Portugal, Experimental investigations and numerical simulation accompanying the HWT test loop operation 